\title{
SIMULASI SISTEM KONTROL OTOMATIS BEBAN TIDAK SEIMBANG
}

\author{
Fanny J. Doringin ${ }^{1}$, Marson James Budiman ${ }^{2}$, Stephy Walukow ${ }^{3}$ \\ ${ }^{1}$ Jurusan Teknik Elektro, Politeknik Negeri Manado, Manado,95252 \\ ${ }^{2}$ Jurusan Teknik Elektro, Politeknik Negeri Manado, Manado,95252 \\ ${ }^{3}$ Jurusan Teknik Elektro, Politeknik Negeri Manado, Manado,95252 \\ E-mail: 1 fannydoringin67@gmail.com
}

\begin{abstract}
Large electric power consumer or consumer with own distribution station, such as Hotel, Office, Shopping center, Industry, etc. The installation is connected with 3 phase electricity, which includes the phase $R$, phase $S$ and phase T. In the planning and installation of electrical installations conducted by Electrical Expert always refers to the design of the load connected in the phase $R, S$ and $T$, which is cultivated in equal (equal), but on the operation (ON / OFF) electrical load can not be regulated load balance on each phase, because the operation $(O N / O F F)$ adjusted to the needs of electrical equipment installed on each phase, resulting in unbalanced loads. Due to unbalanced load in each phase can cause the loss of electric power. The losses of electric power will be greater, if the addition of load or the development of electrical installation is done without regard to the initial design of the installation.

In this research will be made a simulation of control system that will automatically minimize the occurrence of unbalance between phases. The control system will work automatically to adjust the load between phases, by transferring a large detectable load on one phase to a small detectable phase until it is detected that the loads on the $R, S$ and $T$ phases are relatively balanced. In addition, the control system can also detect if one or two missing phases (OFF) occurs, where the system will provide information to the alarm in the form of alarms, indicating that there has been a phase loss, in order for the user to perform a complete electrical outage action for avoid major power losses.

The method used in making the system is the method of research and development, with stages including literature study, field study to obtain data in connection with system manufacture. The next step is designing hardware and software that is simulated through the Proteus program. The next stage is to test the work of the control system based on system algorithms created through the simulation program.

From the test result, when the load unbalance occurs, for example the load detected in the $R$ Phase of 2 Ampere, at $S$ phase 1.5 Ampere and at the T Phase of 1 Ampere, the system will automatically move one of the power lines from Phase $R$ to one of the paths of the T-Phase, so that the overload present in Phase R is overcome by Phase $T$, besides that when indicated there is one phase missing, then the system will inform through the alarm and display on the LCD monitor that there is a phase lost.
\end{abstract}

Keywords: Simulation, control system, spreading, load, unbalanced

\begin{abstract}
Abstrak
Konsumen listrik daya besar atau konsumen yang memiliki gardu distribusi sendiri, seperti Hotel, Perkantoran, Pusat perbelanjaan, Industri, dll penginstalasiannya tersambung dengan listrik 3 fasa, yang meliputi fasa R, fasa $\mathrm{S}$ dan fasa T. Dalam perencanaan dan pemasangan instalasi listrik yang dilakukan oleh instalatir (Ahli kelistrikan) selalu mengacu pada rancangan beban yang tersambung di fasa R, S dan T, yang diusahakan seimbang (sama besar), akan tetapi pada pengoperasiannya (ON/OFF) beban listrik tidak dapat diatur keseimbangan bebannya pada setiap fasa, karena pengoperasian (ON/OFF) disesuaikan dengan kebutuhan dari peralatan listrik yang terpasang pada masing-masing fasa, sehingga terjadi beban tidak seimbang. Akibat beban tidak seimbang di setiap fasa dapat menyebabkan terjadinya rugi-rugi daya listrik. Rugi-rugi daya listrik akan semakin besar, jika penambahan beban atau pengembangan instalasi listrik dilakukan tanpa memperhatikan rancangan awal pemasangan instalasi.

Dalam penelitian ini akan dibuat suatu simulasi sistem kontrol yang secara otomatis akan meminimalis terjadinya ketidak seimbangan beban atar fasa. Sistem kontrol akan bekerja secara otomatis untuk menyesuaikan beban antar fasa, dengan cara memindahkan beban yang terdeteksi besar di salah satu fasa ke fasa yang terdeteksi
\end{abstract}


bebennya kecil, sampai terdeteksi bahwa beban pada fasa R, S dan T relative seimbang. Disamping itu, sistem kontrol ini juga dapat mendeteksi apabila terjadi satu atau dua fasa yang hilang (OFF), dimana sistem akan memberikan informasi kepada penggua berupa alarm, yang menunjuka bahwa telah terjadi kehilangan fasa, agar supaya pengguna dapat melakukan tindakan pemadaman listrik secara keseluruan untuk menghindari terjadinya rugi-rugi daya yang besar.

Metode yang digunakan dalam pembuatan sistem adalah metode riset dan pengembangan, dengan tahapantahapan mencakup studi literatur, studi lapangan untuk memperoleh data-data sehubunagn dengan pembuatan sistem. Tahapan selanjutnya adalah perancangan perangkat keras dan perangkat lunak yang disimulasikan melalui program Proteus. Tahap selanjutnya adalah melakukan uji coba kerja dari sistem kontrol berdasarkan algoritma sistem yang dibuat lewat simulasi program.

Dari hasil pengujian yang dilakukan, saat terjadi ketidak seimbangan beban, sebagai contoh beban yang terdeteksi pada Fasa R sebesar 2 Ampere, pada Fasa S sebasar 1.5 Ampere dan pada Fasa T sebesar 1 Ampere, maka sistem secara otomatis akan memindahkan salah satu jalur kelistrikan dari Fasa $\mathrm{R}$ ke salah satu jalur dari Fasa T, sehingga kelebihan beban yang ada pada Fasa R ditanggulangi oleh Fasa T. disamping itu saat terindikasi ada salah satu fasa yang hilang, maka sistem akan menginformasikan lewat idikator alaram dan tampilan di monitor LCD, bahwa ada fasa yang hilang.

Kata kunci: Simulasi, sistem kontrol, pengatuaran, beban, tak seimbang

\section{PENDAHULUAN}

Beban tidak seimbang di fasa $\mathrm{R}, \mathrm{S}$ dan T akan membuat ada arus yang mengalir dititik netral. Makin besar beban tidak seimbang akan membuat juga makin besar arus yang mengalir pada titik netral. Hal ini membuat ada daya listrik yang terbuang sia-sia atau terjadi rugi-rugi daya. Selain rugi-rugi daya, beban tidak seimbang ini akan memberi kontribusi pada penyaluran daya oleh transformator kurang maksimal.

Untuk meminimal terjadinya rugi-rugi daya listrik yang diakibatkan pengoperasian beban tidak seimbang dan seiring waktu terjadi pengembangan instalasi listrik tanpa memperhatikan perencanaan instalasi listrik awal pemasangan, serta jika terjadi kehilangan satu atau dua fasa lisrik, maka perlu ditambahkan suatu sistem kontrol yang dapat mendeteksi dan mengatur beban di fasa $R$, fasa $S$ dan fasa $\mathrm{T}$ relative seimbang, disamping itu sistem Kontrol yang dibuat juga dapat memberikan informasi kepada pengguna jika terjadi kehilangan satu atau dua fasa agar dapat terhindar dari rugi-rugi daya.

Sistem yang terpadu dalam pembuatan sistem kontrol rugi-rugi dayabeban tidak seimbang menggunakan kontroler Arduino Uno yang berfungsi sebagai pengatur kerja keseluruhan sistem [1][2], sensor arus yang berfungsi sebagai pendeteksi perubahan arus beban [3], sensor tegangan yang berfungsi untuk mendeteksi kehilangan fasa [4], Algoritma program (flowchart) yang berfungsi untuk langkah-langkah yang akan dilakukan dalam pembuatan program dan pemodelan sistem [5][6].

Untuk menjalankan sistem, dibutuhkan program yang ditanamkan kedalam mikrokontroler
Arduino Uno, dimana perangkat lunak yang digunakan untuk pembuatan program adalah Arduino IDE, dengan mengacu pada diagram alir (flowchart) yang dibuat [7].

\section{METODE PENELITIAN}

Dalam menghasilkan suatu model sistem otomatis rugi-rugi daya tidak seimbang, maka dilakukan proses prancangan sistem yang meliputi perancangan model sistem, perancangan perangkat keras, perancangan perangkat lunak, pengujian sistem melalui program simulasi untuk mendapatkan data-data sehubungan dengan kerja sistem.

\subsection{Perancangan Model Sistem}

Perancangan model sistem bertujuan untuk menggambarkan serta menentukan komponenkomponen yang mendukung kerja dari sistem kontrol sistem kontrol otomatis rugi-rugi daya listrik beban tidak seimbang di fasa $\mathrm{R}, \mathrm{S}, \mathrm{T}$.

Model sistem diperlihatkan pada Gambar 1, dengan deskripsi kerja sebagai berikut:

1. Sensor Arus, berfungsi sebagai pendeteksi perubahan arus beban pada jaringan 3 fasa.

2. Sensor pendeteksi fasa hilang, berfungsi untuk mendeteksi kehilangan fasa dari sistem 3 fasa.

3. Kontroler Arduino Uno, yang berfungsi sebagai media pengontrol dalam proses penyeimbangan beban, menggunakan 2 buah kontroler yang berfungsi sebagai master slave.

4. Relai, berfungsi sebagai pemutus dan penyambung supply kelistrikan ke beban. 


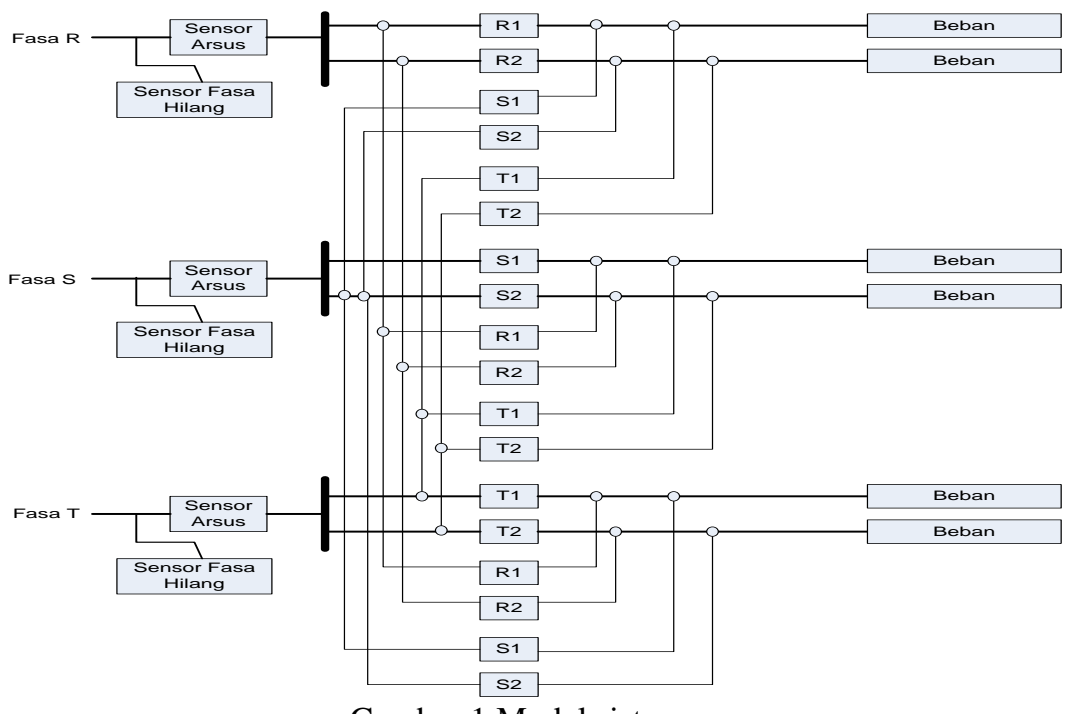

Gambar 1 Model sistem

2.3 Perancangan dan Pembuatan Simulasi Sistem

Perancangan simulasi system dibuat dengan menggunakan program simulasi Proteus, dengan mengatur komponen-komponen penunjang system control sesuai dengan fungsi dan kebutuhannya dalam system. Gambar 2 memperlihatkan rancangan system yang dibuat.

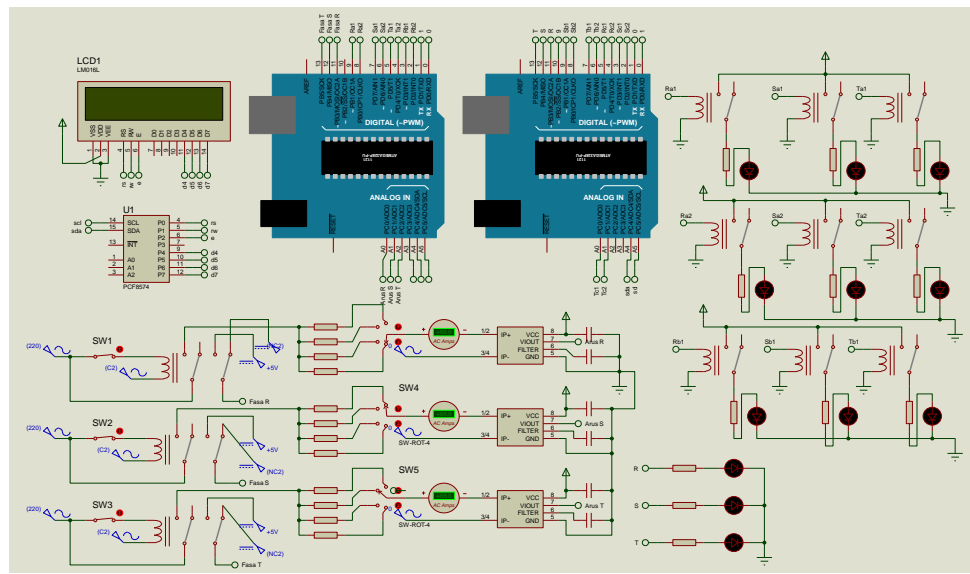

Gambar 2. Rancangan sistem kontrol

\section{HASIL DAN PEMBAHASAN}

Hasil yang dicapai berdasarkan pengujian simulasi sistem dengan tahapan-tahapan pengujian yang dilakukan sebagai perikut:
3.2 Pengujian Saat Fasa $R$, $S$ dan T dalam keadaan seimbang

Gambar 3 memperlihatkan hasil pengujian saat sistem mendeteksi bahwa beban antar fasa dalam keadaan seimbang. 


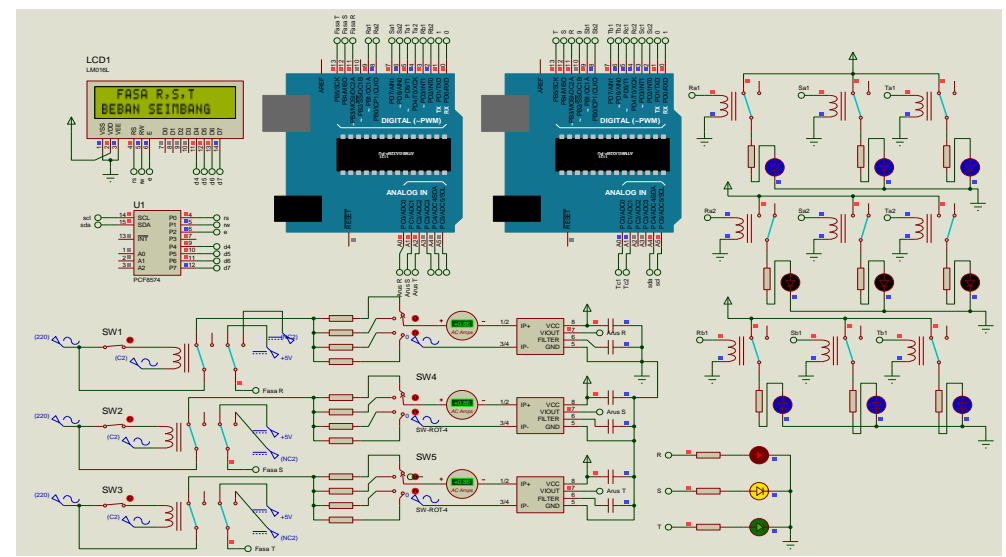

Gambar 3 Pengujian saat beban seimbang

Saat beban terdeteksi dalam keadaan seimbang, dimana besarnya konsumsiarus arus listrik yang terdeteksi melalui sensor arus dari masing-masing fasa, baik fasa $\mathrm{R}$, fasa $\mathrm{S}$ dan Fasa $\mathrm{T}$ sama besar ataupun

3.3 Pengujian Saat Fasa T lebih besar dari fasa $R$ dan fasa $R$ lebih besar dari fasa $S$

Saat sistem mendeteteksi bahwa beban pada fasa $\mathrm{T}$ lebih besar dari beban pada fasa $\mathrm{R}$, sedangkan beban pada fasa $\mathrm{R}$ lebih besar dari beban pada fasa $\mathrm{S}$, maka sistem secara otomatis akan menonaktifkan relay pada salah satu jalur ke beban dari fasa $T$, dan digantikan dengan relay cadangan dari fasa $S$ utnuk menyuplai beban pada jalur $\mathrm{T}$ yang digantikan tersebut, untuk menjaga agar sistem relative dalam keadaan seimbang. Disamping itu juga sistem akan menginformasikan melalui monitor LCD bahwa salah satu jalur ke beban dari fasa $T$ telah digantikan oleh salah satu jalur dasi fasa $S$ untuk menanggulangi kelebihan beban dari fasa $T$. Gambar 4 memperlihatkan pengujian saat fasa $\mathrm{T}$ lebih besar dari fasa $\mathrm{R}$ dan fasa $\mathrm{R}$ lebih besar dari fasa $\mathrm{S}$.

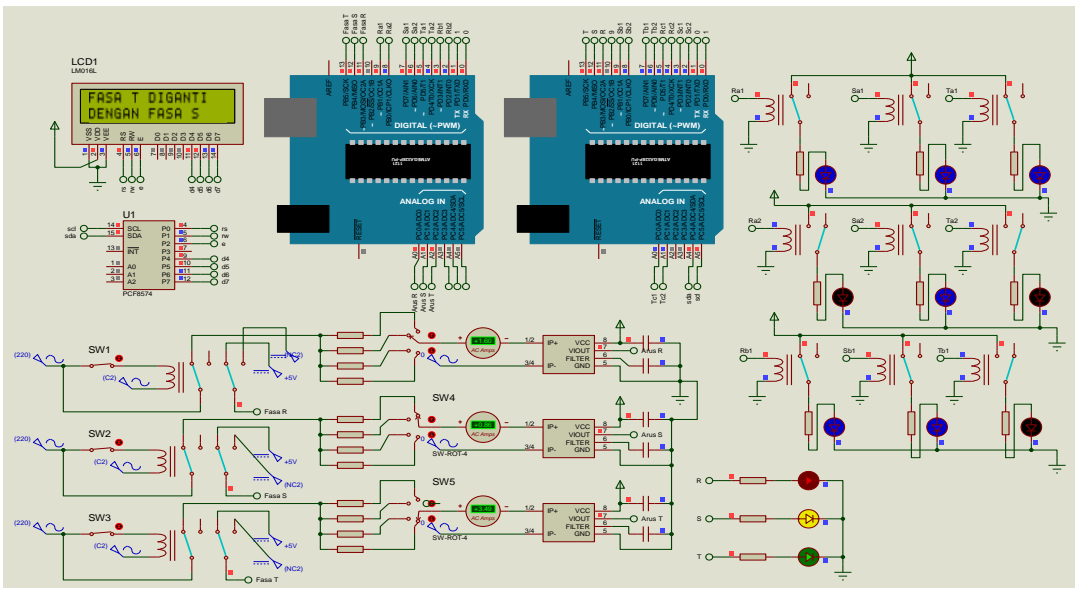

Gambar 4 Pengujian saat fasa $\mathrm{T}>\mathrm{R}>\mathrm{S}$.

3.4 Pengujian Saat Fasa T lebih besar dari fasa $S$ dan fasa S lebih besar dari fasa $R$
Gambar 5 memperlihatkan pengujian saat fasa $\mathrm{T}$ lebih besar dari fasa $\mathrm{S}$ dan fasa $\mathrm{S}$ lebih besar dari fasa R. 


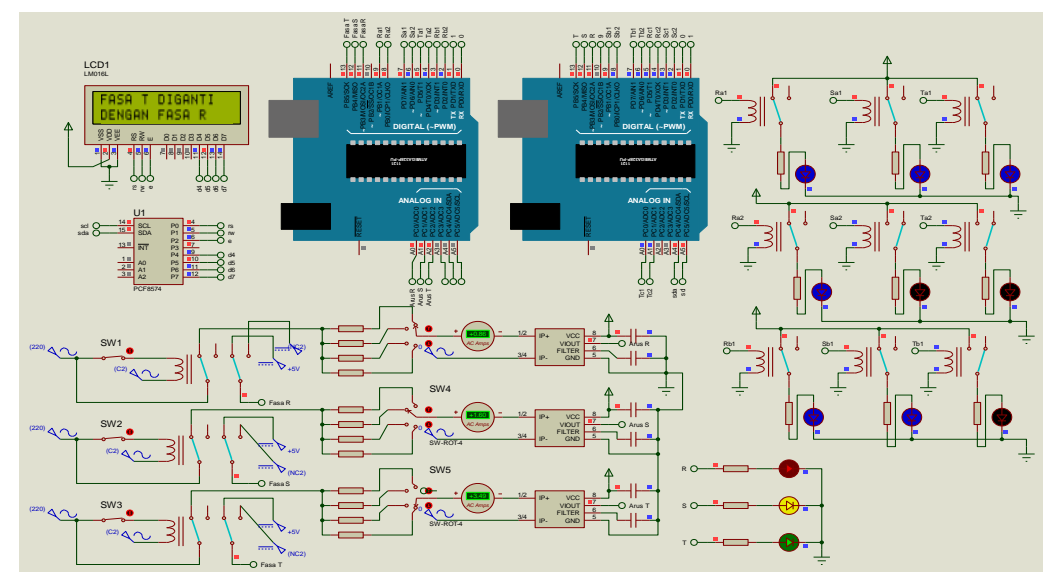

Gambar 5 Pengujian saat fasa $\mathrm{T}>\mathrm{S}>\mathrm{R}$.

Saat sistem mendeteteksi bahwa beban pada fasa $T$ lebih besar dari beban pada fasa $S$, sedangkan beban pada fasa $\mathrm{S}$ lebih besar dari beban pada fasa $\mathrm{R}$, maka sistem secara otomatis akan menonaktifkan relay pada salah satu jalur ke beban dari fasa $\mathrm{T}$, dan digantikan dengan relay cadangan dari fasa $\mathrm{R}$ utnuk menyuplai beban pada jalur $\mathrm{T}$ yang digantikan tersebut, untuk menjaga agar sistem relative dalam keadaan seimbang. Disamping itu juga sistem akan menginformasikan melalui monitor LCD bahwa salah satu jalur ke beban dari fasa $\mathrm{T}$ telah digantikan oleh salah satu jalur dasi fasa $\mathrm{R}$ untuk menanggulangi kelebihan beban dari fasa $\mathrm{T}$.

3.5 Pengujian Saat Fasa T lebih kecil dari fasa $S$ dan fasa S lebih kecil dari fasa $R$
Saat sistem mendeteteksi bahwa beban pada fasa $T$ lebih kecil dari beban pada fasa $S$, sedangkan beban pada fasa $\mathrm{S}$ lebih kecil dari beban pada fasa $\mathrm{R}$, maka sistem secara otomatis akan menonaktifkan relay pada salah satu jalur ke beban dari fasa $\mathrm{R}$, dan digantikan dengan relay cadangan dari fasa $T$ utnuk menyuplai beban pada jalur $\mathrm{R}$ yang digantikan tersebut, untuk menjaga agar sistem relative dalam keadaan seimbang. Disamping itu juga sistem akan menginformasikan melalui monitor LCD bahwa salah satu jalur ke beban dari fasa $\mathrm{R}$ telah digantikan oleh salah satu jalur dasi fasa $\mathrm{T}$ untuk menanggulangi kelebihan beban dari fasa $\mathrm{R}$. Gambar 6 memperlihatkan pengujian saat fasa $T$ lebih kecil dari fasa $\mathrm{S}$ dan fasa $\mathrm{S}$ lebih kecil dari fasa R.

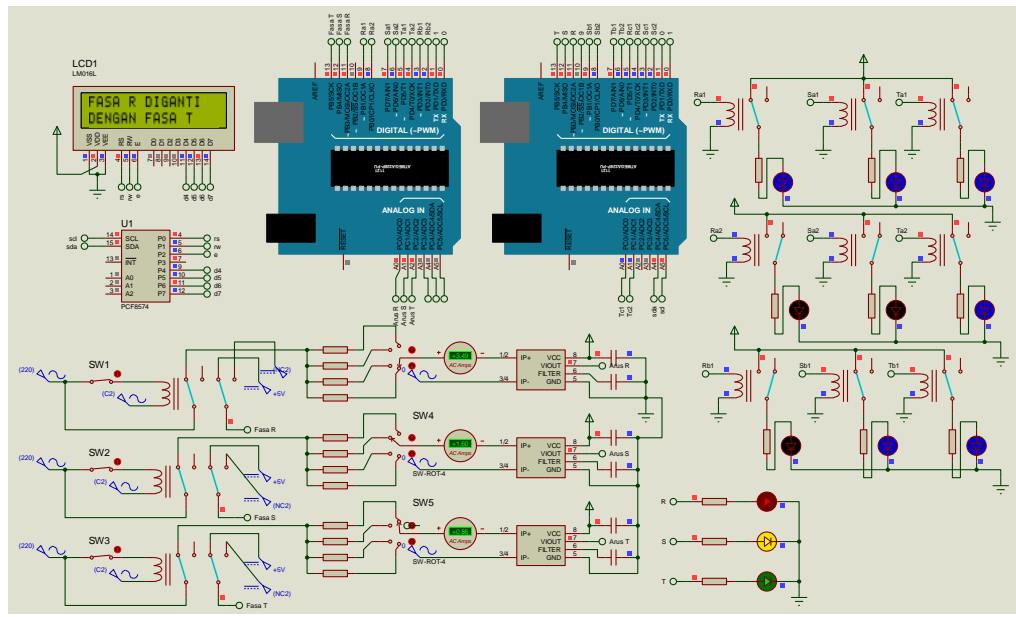

Gambar 6 Pengujian saat fasa $\mathrm{T}<\mathrm{S}<\mathrm{R}$.

\subsection{Pengujian Saat Fasa T lebih kecil dari fasa $R$} dan fasa $R$ lebih kecil dari fasa $S$

Saat sistem mendeteteksi bahwa beban pada fasa $\mathrm{T}$ lebih kecil dari beban pada fasa $\mathrm{R}$, sedangkan beban pada fasa $\mathrm{R}$ lebih kecil dari beban pada fasa $\mathrm{S}$, maka sistem secara otomatis akan menonaktifkan relay pada salah satu jalur ke beban dari fasa $S$, dan digantikan dengan relay cadangan dari fasa $\mathrm{T}$ utnuk menyuplai beban pada jalur $\mathrm{S}$ yang digantikan tersebut, untuk menjaga agar sistem relative dalam keadaan seimbang. Disamping itu juga sistem akan menginformasikan melalui monitor LCD bahwa salah satu jalur ke beban dari fasa $\mathrm{S}$ telah digantikan oleh salah satu jalur dasi fasa $\mathrm{T}$ untuk menanggulangi kelebihan beban dari fasa S. Gambar 7 memperlihatkan pengujian saat fasa $\mathrm{T}$ lebih kecil dari fasa $\mathrm{R}$ dan fasa $\mathrm{R}$ lebih kecil dari fasa $\mathrm{S}$. 


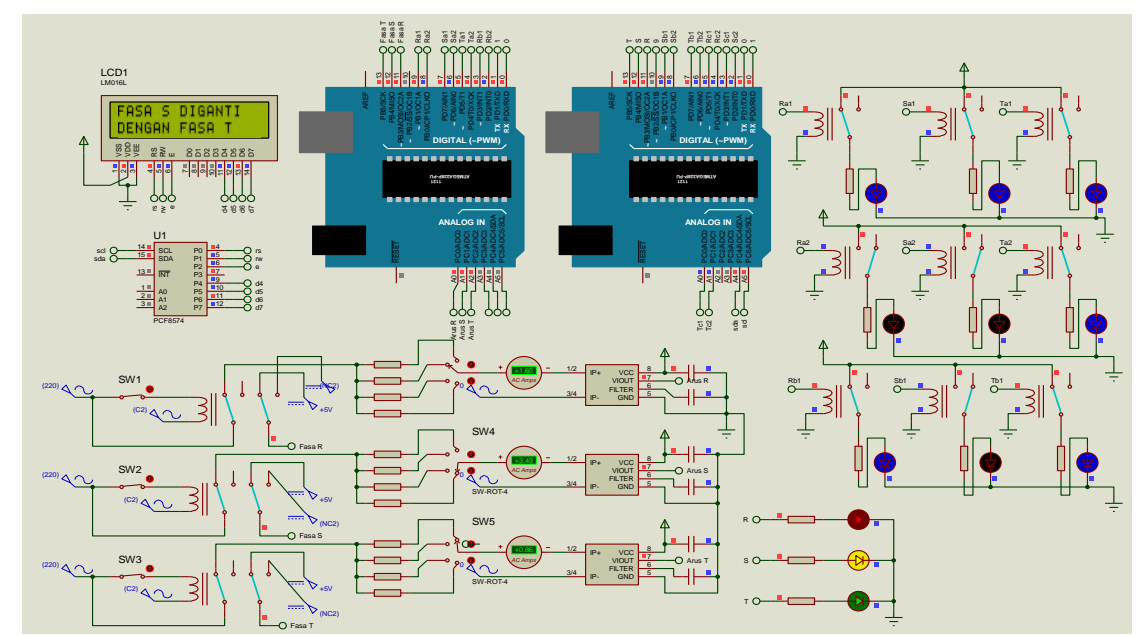

Gambar 7 Pengujian saat fasa $\mathrm{T}<\mathrm{R}<\mathrm{S}$.

3.7 Pengujian Saat Fasa S lebih besar dari fasa $T$ dan fasa $T$ lebih besar dari fasa $R$

Gambar 8 memperlihatkan pengujian saat fasa $\mathrm{S}$ lebih besar dari fasa $\mathrm{T}$ dan fasa $\mathrm{T}$ lebih besar dari fasa R. Saat sistem mendeteteksi bahwa beban pada fasa $\mathrm{S}$ lebih besar dari beban pada fasa $\mathrm{T}$, sedangkan beban pada fasa $\mathrm{T}$ lebih besar dari beban pada fasa $\mathrm{R}$, maka sistem secara otomatis akan menonaktifkan relay pada salah satu jalur ke beban dari fasa $S$, dan digantikan dengan relay cadangan dari fasa $\mathrm{R}$ utnuk menyuplai beban pada jalur $\mathrm{S}$ yang digantikan tersebut, untuk menjaga agar sistem relative dalam keadaan seimbang. Disamping itu juga sistem akan menginformasikan melalui monitor LCD bahwa salah satu jalur ke beban dari fasa $\mathrm{S}$ telah digantikan oleh salah satu jalur dasi fasa $\mathrm{R}$ untuk menanggulangi kelebihan beban dari fasa $\mathrm{S}$.

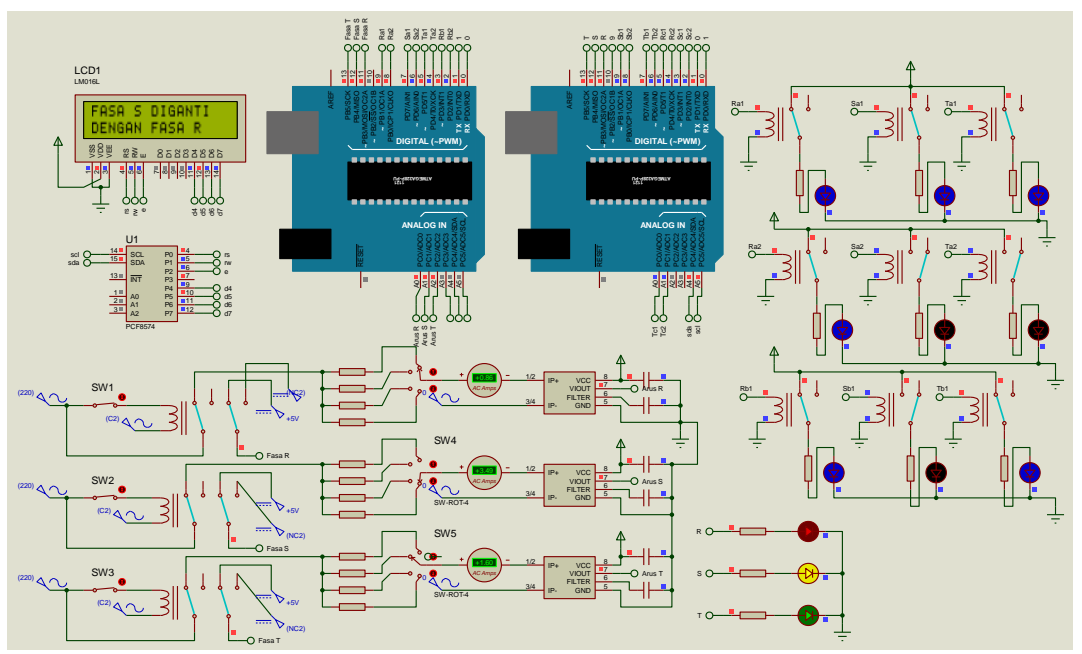

Gambar 8 Pengujian saat fasa $\mathrm{S}>\mathrm{T}>\mathrm{R}$. 


\section{KESIMPULAN}

Dari hasil pengujian yang dilakukan, maka didapat disimpulkan sebagai berikut:

1. Algoritma sistem yang dihasilkan ternyata dapat diimplementasikan ke sistem kontrol otomatis rugi-rugi daya listrik beban tidak seimbang, untuk mengatur keseimbangan beban sehingga dapat meminimalis terjadinya rugi-rugi yang diakibatkan karena ketidakseimbangan beban.

2. Model sistem yang dihasilkan ternyata dapat mendeteksi saat terjadi kehilangan fasa dari beban tiga fasa $\mathrm{R}, \mathrm{S}$ dan $\mathrm{T}$, dimana saat terjadi kehilangan salah satu fasa, misalkan terjadi kehilangan fasa $\mathrm{R}$, maka sistem akan memberikan informasi melalui alaram yang diindikasikan melalui lampu led, dan informasi juga akan ditampilkan melalui monitor LCD prihal kehilangan fasa $\mathrm{R}$ tersebut.

3. Model sistem yang dihasilkan dapat mengatur keseimbangan beban tiga fasa, dengan cara mendeteksi besarnya konsumsi arus listrik dari tiap-tiap fasa dan membandingkannya. Seperti contoh saat terdeteksi bahwa besarnya konsumsi arus listrik dari fasa $\mathrm{R}$ lebih besar dari fasa $\mathrm{S}$, dan besarnya arus fasa $\mathrm{S}$ lebih besar dari fasa $\mathrm{T}$, maka sistem secara otomatis akan memutus jalur ke salah satu beban dari fasa $\mathrm{R}$, kemudian menggantikannya dengan jalur dari fasa $T$.

\section{DAFTAR PUSTAKA}

[1] Afrizal Fitriandi, Endah Komalasari, Herri Gusmedi, 2016, Rancang Bangun Alat Monitoring Arus dan Tegangan Berbasis Mikrokontroler dengan SMS Gateway, Jurnal Rekayasa dan Teknologi Elektro, Volume 10, No. 2.

[2] Ali A.S. Ramschie, Johan F. Makal, Veny V. Ponggawa, 2017, Method of Freon Leak Detection and Dirty Air Filter in Air Conditioning for Electrical Savings, International Journal of Computer Applications, Volume 172 - No.1, August 2017

[3]Ali A.S. Ramschie, Johan Makal, Veny Ponggawa, "Algorithms Air Conditioning Air Filter Detection System For Electric Energy Savings", International Journal of Computer Application (IJCA), Vol. 156 No. 8, 2016.

[4] Alan G. Smith, "Introduction To Arduino," Alan G. Smith, 2011.

[5]Sujadi, MT, 2005, Teori dan Aplikasi Mikrokontroler, Cetakan Pertama, Graha Ilmu, Yogyakarta.

[6] Allegro mikrosistem.inc. "Datasheet ACS712".

[7] Syahwil, Muhammad. 2013. Panduan Mudah Simulasi Dan Praktek Mikrokontroler Arduino. Andi. 